\title{
Abstracts
}

\section{Economics and Care Services}

Kenneth Wright

Stefan Håkanson, 'Economic aspects of care of the elderly'. Effective Health Care, 2 (1985), 239-245.

Like many governments in Western Europe, the Swedish Government is concerned about the resource consequences of the growing number in their population of very elderly people who will need some form of state care or assistance. Long-term estimates of age-standardised costs show that in Sweden health care and social-service expenditure on the aged must increase by an average annual rate of $1.3 \%$ in order to maintain standards of care which existed at the beginning of the I $980 \mathrm{os}$.

This concern has focused attention on the need to allocate resources efficiently, especially on the provision of a cost-effective mix of alternative forms of long-term care. Dr Håkanson points out that there has been very little rigorous evaluation of this topic either in Sweden or in other countries. In order to obtain some information on this important policy question, an economic study was carried out in two localities in Sweden to ascertain what factors were involved in the transfer from one form of care to another. These studies revealed that there were considerable misallocations of resources in different forms of care arising mainly out of the premature admission of people to long-term institutional care or the failure to discharge from institution to home care. The results from the local studies were then used to estimate the cost savings that would result nationwide from a reallocation of resources to improve home care instead of institutional care. If the situation in one locality (Sundsvall) were typical of Sweden as a whole, at least I,259 million Kroner would be saved by substituting home for institutional care, whereas in the other study area (Vetlanda) this minimum estimate was reduced to 680 million Kroner.

\section{COMMENT}

As the article pointed out, there is a shortage of rigorous evaluation work on the cost-effectiveness of alternate forms of care for the elderly. The problems of measuring all the costs involved, as well as the 
effectiveness of different forms of care, militate against the conduct of this type of economic appraisal. Because of time and other constraints the Swedish study was forced to omit some of the crucial aspects of the comparative efficiency of different forms of care. No regard was had for the costs of informal care at home, or for the preferences of the people being cared for in hospitals or other institutions. Thus, like many other studies of this question, attention is focused on public sector cost comparisons whilst efficiency requires the study of relative outcomes as well as relative costs, falling on the private as well as the public sector. Economists are well aware of these problems and are keen to collaborate in inter-disciplinary studies which might tackle some of the many outstanding problems which abound in this aspect of policy analysis.

David Challis and Bleddyn Davies, 'Decentralised Budgeting and Care for the Elderly'. Public Money, 5 (1985), 2 I-24.

The authors of this article are also concerned with transfers of elderly people between different forms of care. The criterion that the Secretary of State has asked professional staff responsible for deciding on these transfers to take into account is concerned with cost-effectiveness and targeting. The aim of this criterion is to ensure that people obtain the 'right' mix of services at the lowest cost. The meeting of this criterion requires the professional staff to operate a complex information system which can indicate which services are appropriate to individual circumstances as well as the costs of providing these services. It is pointed out that research has indicated that such information is not usually available to staff in social services departments, that public services often cannot anyway respond to certain circumstances (e.g. personal care at night) and that co-ordination is lacking between the several agencies responsible for delivering these services.

In order to combat the problem Kent County Council has instituted a community care scheme by which social workers receive a budgeted allowance to provide a set of services which they thought would best meet the requirements of the elderly person they were helping. The freedom to use this budget encouraged social workers to provide what they considered to be the 'right' mix of services whilst making them aware of the costs of their decision. In addition the freedom to use the budget allowed them to pay for services which are provided on a private or informal basis and removed the restrictions which frequently bedevil the statutory services.

The results of the scheme are most encouraging. The people being 
helped under the protocol of the community care scheme are functioning better on the whole than the people in the control group. A significantly greater proportion of people in the community care scheme were being cared for at home and a significant proportion were surviving longer. These outcomes were also achieved at lower cost than those of the control group. The evaluation is now in its fourth follow-up year and is trying to discover if and when the costs of community care become greater than institutional care for some groups of elderly people.

\section{GOMMEN T}

This article shows the importance of developing evaluative studies at a local level which contain measures of cost and outcome and can also be generalised to other parts of the country. The use of a key social worker to tailor service delivery to individual circumstances within a constrained budget is the nearest public sector analogy to the economist's model of individual consumer choice. The results of this project are eagerly awaited throughout many different countries and if successful it could provide a model of case management which is of importance to all people requiring long-term medical and social care.

Centre for Health Economics, University of York

\section{Social Support}

\section{Mildred Blaxter}

Nancy J. Chapman and Diane L. Pancoast, 'Working with the informal helping networks of the elderly: the experiences of three programs'. $\mathcal{J}$. of Social Issues, 4I (1985), 47-63.

Three demonstration projects intended to develop ways of strengthening the informal helping networks of elderly people are reviewed. The first, in Portland, Oregon, used homemakers to enhance the existing networks of their clients. The second, in Quebec, used a network approach in responding to requests for services, finding alternatives to nursing home placements, or interweaving formal and informal resources to provide services in the home. The third, in New York City, hoped to maximise the use of, and sensitise staff to, the active social networks which existed in single-room occupancy hotels largely housing the elderly and former mental patients.

The review focuses particularly on a comparison of the goals of 